\title{
$\mathrm{LDPC}$ 로 부호화된 $\mathrm{OFDM}$ 시스템에서 수렴 속도를 개선시킨 복호 방법을 적용한 균등 결합 전력 할당 재전송 기법
}

장 민 호*

\section{Retransmission Scheme with Equal Combined Power Allocation Using Decoding Method with Improved Convergence Speed in LDPC Coded OFDM Systems}

\author{
Min-Ho Jang \\ 요 약
}

본 논문은 type I 혼합-자동 반복 요구 (hybrid automatic repeat request: H-ARQ) 시스템에서 저밀도 패리티 검사 (low-density parity-check: LDPC)로 부호화된 직교 주파수 분할 다중화 (orthogonal frequency division multiplexing: OFDM) 서브프레임의 전송 순서를 균등 결합 전력이 할당되도록 조정한 재전송 방법 ${ }^{[7]}$ 을 기초로 성 능 개선을 채널 용량을 사용하여 분석하고, 계층 복호 방법 ${ }^{[4]}$ 을 적용하여 H-ARQ 재전송 기법의 수렴 속도 개선 을 확인한다. 구체적으로 임의의 서브프레임 재전송 패턴에 대하여 채널 용량이 클수록 비트오류율 (bit error rate: $\mathrm{BER})$ 성능도 우수하다는 사실을 검증한다. 그러므로 각 서브프레임에 대하여 균등 결합 전력 할당을 보장하는 서 브프레임 재전송 패턴은 채널 용량을 최대로 하며, 임의의 다른 서브프레임 전송 순서 조정을 통한 재전송 패턴보 다 성능이 우수하다. 결국 균등 결합 전력 할당을 만족하도록 서브프레임 순서를 조정하는 재전송 방법은 기존 체 이스 결합 (Chase combining)보다 복호 복잡도를 증가시키지 않으면서도 주목할 만한 성능 개선을 보인다.

Key Words : Convergence speed, Channel capacity, H-ARQ, LDPC codes, OFDM systems

\section{ABSTRACT}

In this paper, we introduce the low-density parity-check (LDPC) coded orthogonal frequency division multiplexing (OFDM) subframe reordering scheme $^{[7]}$ for achieving equal combined power allocation in type I hybrid automatic repeat request (H-ARQ) systems and analyze the performance improvement by using the channel capacity. Also, it is confirmed that the layered decoding ${ }^{[4]}$ for subframe reordering scheme in H-ARQ systems gives faster convergence speed. It is verified from numerical analysis that a subframe reordering pattern having larger channel capacity shows better bit error rate (BER) performance. Therefore the subframe reordering pattern achieving equal combined power allocation for each subframe maximizes the channel capacity and outperforms other subframe reordering patterns. Also, it is shown that the subframe reordering scheme for achieving equal combined power allocation gives better performance than the conventional Chase combining scheme without increasing the decoding complexity.

※ 본 논문은 2011년 울산과학대학교 교내학술연구비 지원에 의해 수행된 연구 결과입니다.

- 주저자 : 울산과학대학교 전기전자공학부, mhjang @uc.ac.kr, 종신회원

논문번호 : KICS2013-04-197, 접수일자 : 2013년 4월 29일, 최종논문접수일자 : 2013년 9월 11일 


\section{I. 서 론}

최근 스마트 폰의 폭발적인 보급으로 인하여 데이 터 패킷 사용량은 기하급수적으로 증가하고 있다. 이 에 따라 차세대 이동 통신 시스템에서는 대용량 고속 데이터의 신뢰도 높은 송수신이 필수적으로 요구된다. 이러한 무선 환경에서 신뢰도 높은 통신을 보장하기 위하여 핵심적인 두 가지 요소 기술로 고속 데이터 전 송에 적합한 변조 방식인 직교 주파수 분할 다중화 (orthogonal frequency division multiplexing: OFDM) 시스템과 전송 효율을 개선하여 시스템 전체의 성능 을 향상시킬 수 있는 오류정정부호에 대한 다양한 연 구가 진행되었다.

OFDM 시스템은 주파수 선택적 페이딩 (frequency selective fading) 채널에서 하나의 탭을 갖는 이퀄라 이저 (equalizer)를 사용하여 구현이 가능하기 때문에, 단일 반송파 (carrier) 변조 방식을 사용하는 시스템보 다 성능이 우수 ${ }^{1]}$ 하다. 또한 데이터 패킷 전송 과정에 서 잡음, 간섭 및 페이딩과 같은 채널의 특성에 따라 발생하는 오류에 의한 정보 손실을 줄이기 위하여 다 양한 오류정정부호가 사용되고 있다. 특히 Gallager에 의하여 1962년에 소개된 저밀도 패리티 검사 (low-density parity-check: LDPC) 부호 ${ }^{[2]}$ 는 Shannon 이 제시한 채널 용량에 근접하는 탁월한 오류정정 성 능에도 불구하고, 당시 반복복호를 기반으로 하는 복 호 알고리즘의 많은 계산량을 하드웨어에서 처리할 수 없었기 때문에 1990년대 이전에 큰 주목을 받지 못하였다. 최근 하드웨어 기술의 비약적인 발전에 힘 입어 대용량 고속 데이터 처리에 적합한 LDPC 부호 가 많은 응용 분야에서 재조명되고 있다. 실제로 $\mathrm{LDPC}$ 부호를 적용한 OFDM 시스템은 광대역 무선 접속 (broadband wireless access)을 위한 모바일 와이 맥스 (mobile worldwide interoperability for microwave access: Mobile WiMAX)와 무선 근거리 망 (wireless local area network: WLAN), 그리고 디 지털 비디오 방송 (digital video broadcasing: DVB) 과 같이 통신 및 방송과 관련된 다양한 분야에서 표준 으로 채택되어 사용되고 있다.

Belief propagation (BP) 반복복호 알고리즘 ${ }^{[3]}$ 은 $\mathrm{LDPC}$ 부호의 대표적인 복호 방법이다. 하지만 이러 한 복호 알고리즘은 신뢰할 만한 정보를 복원하기 위 하여 복호 과정에서 많은 반복 계산 과정을 필요로 하 며 이는 결과적으로 계산 복잡도를 커지게 하기 때문 에 구현상 제한 요인이 될 수 있다. 그리하여 복호 과 정에서 계산의 복잡도를 줄이기 위하여 LDPC 부호에
대한 성능의 수렴 속도 개선을 위한 계층 복호 방법이 제인 ${ }^{[4,5]}$ 되었다. 이러한 계층 복호 알고리즘은 고속 대 용량 데이터의 실시간 처리에 적합하다.

Type I 혼합-자동 반복 요구 (hybrid automatic repeat request: H-ARQ) 기법이 적용된 시스템은 복 호 과정에서 오류가 발생한 경우, 재전송시 이전 전송 과 동일한 패킷을 재전송한다. 수신단에서는 재전송 이후 복호 과정에서 이전 전송에서 오류가 발생한 패 킷은 이용되지 않는다. Type I H-ARQ 시스템에서 $\mathrm{LDPC}$ 로 부호화된 $\mathrm{OFDM}$ 서브프레임의 새로운 재전 송 방법은 기존 체이스 결합 (Chase combining) ${ }^{[6]}$ 을 이용한 재전송 방법보다 비트오류율 (bit error rate: $\mathrm{BER})$ 성능이 우수하다는 사실을 보였다 ${ }^{[7]}$.

본 논문은 [7]에서 제시된 $\mathrm{LDPC}$ 로 부호화된 OFDM 서브프레임의 새로운 재전송 방법을 기초로 성능 개선을 분석하고 수렴 속도 개선을 위한 계층 복 호 방법을 적용하여 재전송 기법의 성능을 분석한다. 구체적으로 임의의 패킷을 고정된 개수의 동일한 크 기의 서브프레임으로 나누고, H-ARQ 시스템에서 패 킷 전송 과정에서 각 서브프레임에 대하여 균등 결합 전력 할당 (equal combined power allocation)이 이루 어지도록 서브프레임의 전송 순서를 재조정하였을 때 의 성능 측면에서의 이득을 검증한다. 아울러 H-ARQ 시스템 복호 과정에서 수렴 속도 개선을 위한 계층 복 호 방법을 적용하여 재전송시 반복 횟수에 따른 성능 을 분석하고자 한다. 수렴 속도 개선은 반복 횟수를 감소시킬 수 있다는 의미에서 계산 복잡도를 줄일 수 있기 때문에 하드웨어 구현 측면에서 매우 중요하다.

본 논문은 다음과 같이 구성되어 있다. ㅍㅈ장에서 수 렴 속도 개선을 위한 계층 복호 알고리즘을 소개한다. III장은 H-ARQ 시스템 환경에서 체계적인 분석을 위 하여 필요한 시스템 모델 및 채널 모델을 제시하고, 재전송시 균등 결합 전력 할당이 되도록 서브프레임 의 전송 순서를 조정하는 재전송 기법에 대하여 소개 한다. IV장에서는 H-ARQ 시스템에서 균등 결합 전력 할당을 보장하도록 서브프레임의 전송 순서를 재조정 하였을 경우에 그 성능이 가장 우수하다는 사실을 채 널 용량을 이용하여 규명한다. $\mathrm{V}$ 장에서는 모의실험 결과로부터 $\mathrm{H}-\mathrm{ARQ}$ 시스템에서 제안된 균등 결합 전 력 할당을 보장하도록 OFDM 서브프레임 전송 순서 를 재배치하는 방법의 이득 및 계층 복호 방법을 적용 한 재전송 기법의 수렴 속도 개선을 확인한다. 마지막 으로 VI장에서 본 논문의 결론을 제시한다.

\section{II. 계층 복호 알고리즘}


이번 장에서는 LDPC 부호에 대한 복호기 구현에 서의 계산 복잡도를 감소시키기 위하여 제안된 계층 복호 알고리즘 ${ }^{[4]}$ 을 소개한다. 변수 노드의 개수가 $n$ 개 이고, 체크 노드의 개수가 $m$ 개이며 부호율이 $1-m / n$ 인 LDPC 부호를 고려하자. 편의를 위하여 $m$ 개의 체크 노드는 $p$ 개의 subset으로 분할된다고 가 정하면, 각각의 subset은 $m / p$ 개의 체크 노드로 구성 되어 있다. 이때 계층 복호가 가능하기 위하여, 임의 의 subset 내부에 존재하는 체크 노드들에 의하여 연 결되어 있는 각각의 변수 노드는 최대 한 번의 연결만 을 갖도록 subset이 분할될 수 있도록 조정이 필요하 다. 이제 첫 번째 subset에 대하여, 각각의 변수 노드 는 첫 번째 subset 내부에 존재하는 이웃한 체크 노드 로 갱신한 메시지 (updated message)를 보낸다. 그러 면 첫 번째 subset 내부에 존재하는 체크 노드 메시지 를 갱신하여 자신과 이웃한 변수 노드로 메시지를 보 낸다. 이상의 메시지 갱신 과정이 남아있는 $(p-1)$ 개 의 체크 노드 subset에 대하여 연속적으로 수행된다. $p$ 개의 subset에 대하여 모든 메시지 전달이 수행되면 반복복호의 한 번의 반복 (iteration)이 완료되었다고 말한다. 그러므로 계층 복호 과정에서 한 번의 반복에 대한 계산량은 기존 복호 방법의 한 번의 반복에 대한 계산량과 동일하다. 이러한 LDPC 부호의 계층 복호 방법은 갱신된 메시지 교환으로 인하여 기존 복호 방 법과 비교하여 신뢰도 전파가 빠르며 이에 비례하여 수렴 속도도 개선된다. 다시 말해서, 계층 복호 방법 은 기존 복호 방법과 동일한 성능을 얻기 위하여 반복 횟수를 줄일 수 있는 장점을 갖는다.

\section{III. 시스템 모델과 서브프레임 재전송 기법}

다중경로 페이딩에 대한 간단한 채널 모델로 two-ray 전파 모델 ${ }^{[8]}$ 을 고려할 수 있다. 특히 본 논문 은 실내 혹은 보행 환경에서 무선 근거리 망을 사용하 는 경우와 같이 채널 상태가 매우 느리게 변화하는 주 파수 선택적 채널에 초점을 맞추고 있기 때문에, type I H-ARQ 시스템에서 이전 패킷에 오류가 발생하여 재전송이 수행될 경우에 채널 상태는 거의 변하지 않 는다고 가정할 수 있다. 또한 하나의 패킷을 구성하는 각각의 심볼 (symbol)은 OFDM 시스템의 각 부반송 파 (subcarrier)에 할당되며, 보호 대역 (guard band)는 고려하지 않는다. 이때 각각의 $\mathrm{LDPC}$ 부호어 (codeword)는 하나의 패킷을 구성한다고 가정한다. 아울러 패킷은 LDPC 부호로 부호화되어 이진 위상천 이 키잉 (binary phase-shift keying: BPSK) 변조 방
식 혹은 16-QAM (quadrature amplitude modulation) 변조 방식을 이용하여 OFDM 서브프레임으로 전송된 다.

이제 채널의 주파수 선택적 페이딩 특성을 two-ray 전파 모델로 모델링한다면, 채널은 $s$-번째 심볼, $1 \leqq s \leqq N_{s}$,에 대하여 주파수 영역에서 다음 수식과 같이 나타낼 수 있다.

$$
h(s)=1+\exp (j \theta) \exp \left(j \frac{d \times 2 \pi s}{N_{s}}\right)
$$

여기서 $\theta$ 는 $[0,2 \pi)$ 구간에서 균일 분포 (uniform distribution)를 따르는 랜덤 변수이고, $N_{s}$ 는 하나의 패킷 내에 심볼의 개수를 의미한다. 또한 $d$ 는 패킷 duration에서 딥 (deep) 페이딩의 개수를 나타낸다. 본 논문에서 결과는 주로 $d=1$ 인 단일 딥 페이딩 (signle deep fading)에 대하여 제시되었으며, $d$ 가 2 혹은 3 인 경우에 대한 결과도 단일 딥 페이딩에서와 유사한 경 향성을 확인할 수 있다.

체이스 결합은 type I H-ARQ 시스템에서 복호를 위하여 적용 가능한 가장 간단한 결합 기법으로 $\mathrm{H}-\mathrm{ARQ}$ 를 지원하는 많은 시스템에서 채택하고 있는 결합 방식이다. 체이스 결합의 개념은 다음과 같이 간 략하게 설명될 수 있다. 수신된 패킷이 복호에 실패하 여 오류가 발생하면, 패킷의 재전송이 요구된다. 수신 단은 해당 패킷을 재전송 받아서 이전 전송에서 오류 를 포함하고 있던 수신 패킷과 심볼 단위로 순서대로 더한다. 결국 복호 과정은 이러한 결합 값들을 이용하 여 수행될 수 있다.

이제 체이스 결합에 의한 재전송 기법의 성능을 개 선하기 위하여, H-ARQ 시스템에서 채널 상태 정보 (channel state information: CSI)를 이용할 수 있는 경 우와 그렇지 못한 환경으로 구분하여 각 서브프레임 에 대하여 균등 결합 전력이 할당되도록 서브프레임 의 전송 순서를 조정하는 재전송 기법에 대하여 살펴 보자. 물론 H-ARQ 시스템에서 CSI를 활용하기 위해 서는 피드백 채널 (feedback channel)을 사용하기 때 문에 추가적인 오버헤드 (overhead)가 발생한다. 그러 므로 CSI를 이용하지 않는 재전송 기법이 실제 시스 템을 구현하는데 가치가 높을 수 있으며, 본 논문에서 도 여기에 초점을 맞추어 논의를 진행한다.

\section{1. 채널 상태 정보를 이용하는 방법} 채널 추정을 통하여 CSI를 이용할 수 있는 OFDM 시스템을 고려하자. 첫 번째 전송을 위하여, 각각의 
패킷을 순서대로 동일한 크기의 $M$ 개의 서브프레임으 로 나누고, CSI를 이용하여 각 서브프레임의 심볼들 에 대한 전력을 계산한다. 그 후 첫 번째 전송에서, 하 나의 패킷 내의 $M$ 개의 서브프레임에 대하여 채널 상 태가 좋은 서브프레임에 패킷의 메시지 부분을 할당 하고 채널 상태가 좋지 않은 서브프레임에는 패리티 부분을 할당하는 방법으로 패킷 내의 부호어의 위치 를 서브프레임 단위로 전송 순서를 조정하여 전송한 다.

수신단에서는 재조정된 서브프레임의 순서에 맞추 어 복호 과정을 진행한다. 복호가 실패한 패킷에 대해 서는 $\mathrm{H}-\mathrm{ARQ}$ 를 이용한 재전송이 요청된다. 재전송시 에는 각 서브프레임에 대하여 균등 결합 전력이 할당 될 수 있도록 하기위하여 첫 번째 전송 때와는 반대 로, 채널 상태가 좋은 서브프레임에 패킷의 패리티 부 분을 할당하고 채널 상태가 좋지 않은 서브프레임에 패킷의 메시지 부분을 할당한다. 만일 복호 후 여전히 오류가 발생하여 재전송이 추가적으로 필요할 경우, 세 번째 및 네 번째 전송 과정에서는 각각 첫 번째 및 두 번째 전송의 서브프레임 재조정 패턴을 교대로 적 용할 수 있다.

\section{2. 채널 상태 정보를 이용하지 않는 방법}

CSI를 이용할 수 없는 환경에서, 재전송 이후에 시 스템 성능 개선을 위한 방법을 소개한다. 먼저, CSI를 송신단에서 이용할 수 없기 때문에, 서브프레임에 대 하여 특별히 순서 조정을 하지 않고 차례대로 첫 번째 전송을 수행한다. 이런 과정에 의하여 수신 받은 패킷 에서 오류가 검출되어 두 번째 전송이 필요할 경우에 서브프레임의 순서를 조정하는 재전송 기법을 다음과 같이 적용할 수 있다. 각 패킷을 주파수 영역에서 동 일한 크기를 갖는 $M$ 개의 서브프레임으로 분할하여, 주어진 페이딩 채널에 대하여 주파수 영역에서 각각 의 결합 서브프레임의 평균 전력이 최대한 균등하게 되도록 서브프레임 재전송 패턴을 사전에 결정할 수 있다. 그러면 H-ARQ을 지원하는 시스템에서 하나의 패킷 내의 서브프레임들은 각 서브프레임의 평균 전 력의 누적 합이 균등해 지도록 순서를 재조정하여 첫 번째 전송에서와 동일한 채널로 재전송된다. 채널이 매우 느리게 변화하는 페이딩 채널을 고려하였기 때 문에 재전송시에도 첫 번째 전송 때와 동일한 채널을 이용한다고 가정할 수 있다. 또한 평균 전력을 구하기 위하여 채널 모델은 사전에 알려져 있다고 가정한다. 결국 송신단과 수신단에서 서브프레임 재전송 패턴을 모두 알고 있다고 할 수 있다.
$\mathrm{LDPC}$ 로 부호화된 OFDM 시스템에서 각 서브프레 임의 전력이 비균등하게 할당되었을 경우 시스템의 성능이 열화됨을 다수의 모의실험 결과로부터 예측할 수 있다. 이러한 결과들로부터 재전송 이후 결합 서브 프레임에 균일 전력 할당을 보장하도록 순서를 조정 하는 재전송 기법이 제안되었다. 이러한 재전송 기법 은 딥 페이딩을 경험한 서브프레임의 대부분이 재전 송 과정에서 균등 전력이 되도록 결합되어 딥 페이딩 효과가 상쇄되기 때문에 성능이 개선될 것이라고 예 측할 수 있다. 서브프레임의 전송 순서를 조정하는 재 전송 방법의 성능 개선에 대한 보다 상세한 이유는 채 널 용량을 사용하여 다음 장에서 분석될 것이다.

첫 번째 전송 과정에서 패킷 내에 복호기에서 정정 할 수 없는 오류가 발생하였을 경우에 OFDM 시스템 은 재전송을 필요로 한다. 재전송은 미리 결정된 서브 프레임의 순서에 따라 수행되며, 수신단에서 결합 수 신 신호에 대하여 복호 과정을 진행한다. 신뢰도 높은 통신을 위하여 추가적으로 세 번째, 네 번째 전송이 필요하다면 결합 신호에 대하여 균등 전력 할당이 이 루어지도록 서브프레임의 전송 순서를 조정하는 재전 송 방법이 연속적으로 적용될 수 있다.

\section{IV. 채널 용량을 이용한 서브프레임 전송 순서 결정}

이 장에서는 $\mathrm{H}-\mathrm{ARQ}$ 시스템에서 패킷 전송시 $\mathrm{OFDM}$ 서브프레임의 전송 순서를 균등 결합 전력 할 당을 보장하도록 조정하여 재전송할 경우에 그 성능 이 가장 우수하다는 사실을 채널 용량을 이용하여 규 명한다.

입력이 $X$ 이고 출력이 $Y$ 인 이진 입력 가산 백색 가우시안 잡음 (binary input additive white Gaussian noise: BIAWGN) 채널에서 상호 정보량 (mutual information) ${ }^{[9]}$ 은 다음과 같이 계산할 수 있다.

$$
I(X ; Y)=\iint f(x, y) \log \frac{f(x, y)}{f(x) f(y)} d x d y
$$

여기서 $f(x)$ 와 $f(y)$ 는 각각 확률 변수 $\mathrm{X}$ 와 $\mathrm{Y}$ 의 확 률 밀도 함수 (probability density function)를 나타내 고, $f(x, y)$ 는 결합 확률 밀도 함수를 의미한다. 또한, 채널 용량은 상호 정보량의 최대값으로 나타낼 수 있 으며, 상호 정보량 $I(X ; Y)$ 는 확률 변수 $X=\{x \in\{-1,+1\}\}$ 가 균일하게 분포 되었을 경우 에 최대값을 갖는다. 그러므로 채널 용량 $C$ 는 다음과 
같이 유도할 수 있다.

$$
\begin{aligned}
C=\max & \{I(X ; Y)\} \\
=1 & -\int_{-\infty}^{+\infty} \frac{1}{\sqrt{2 \pi \sigma^{2}}} \exp \left(-\frac{\left(y-\sqrt{E_{s}}\right)^{2}}{2 \sigma^{2}}\right) \\
& \times \log \left[1+\exp \left(-\frac{2 \sqrt{E_{s}}}{\sigma^{2}} y\right)\right] d y
\end{aligned}
$$

여기서, $E_{s}$ 와 $\sigma^{2}$ 은 각각 심볼의 에너지와 잡음의 분 산 (variance)을 나타낸다. 또한 $\mathrm{H}-\mathrm{ARQ}$ 를 지원하는 시스템의 재전송 과정에서 $\quad E_{s}=\left|h_{1}(s)\right|^{2}$ $+\left|h_{2}(s)\right|^{2}$ 이고, $\sigma^{2}=\left(\left|h_{1}(s)\right|^{2}+\left|h_{2}(s)\right|^{2}\right) \sigma_{n}^{2}$ 이 다. 이때, $h_{1}$ 과 $h_{2}$ 는 각각 첫 번째 전송과 두 번째 전 송에서의 채널 특성을 나타낸다.

이제, 채널 용량이 최대가 되도록 하기 위하여 한 패킷 내의 서브프레임의 전송 순서를 조정하는 방법 에 대하여 살펴보자. 이를 위하여 우선 각 서브프레임 의 전력을 계산한다. 하지만 CSI를 이용할 수 없는 시 스템에 대해서는 수식 (1)에서 제시되어 있는 $\theta$ 를 알 수 없기 때문에, 각 서브프레임의 전력을 직접적으로 계산할 수 없다. 그러므로 이러한 경우에는 전력을 평 균적으로 계산한다. 먼저 수식 (1)을 이용하여 $|h(s)|^{2}$ 을 다음과 같이 계산할 수 있다.

$$
|h(s)|^{2}=2+2 \cos \left(\theta+\frac{d \times 2 \pi s}{N_{s}}\right)
$$

그러므로 각 서브프레임의 평균 전력은 다음과 같 이 유도할 수 있다.

$$
p_{i}=\frac{M}{N_{s}} \int_{\frac{2 \pi}{M} i}^{\frac{2 \pi}{M}(i+1)} \sum_{s=0}^{\frac{N_{s}}{M}-1}|h(s)|^{2} d \theta
$$

여기서 $p_{i}, 0 \leqq i \leqq M-1$,는 $i$-번째 서브프레임의 평균 전력을 의미하며, $M$ 은 하나의 패킷에 있는 서 브프레임의 개수를 나타낸다. 또한 각 서브프레임은 $N_{s} / M$ 개의 BPSK 심볼을 포함한다.

수식 (4)와 (5)로부터, 각 서브프레임의 평균 전력 을 다음과 같이 표현할 수 있다.

$$
p_{i}=\frac{M}{N_{s}} \int_{\frac{2 \pi}{M} i}^{\frac{2 \pi}{M}(i+1)} \sum_{s=0}^{\frac{N_{s}}{M}-1}\left[2+2 \cos \left(\theta+\frac{d \times 2 \pi s}{N_{s}}\right)\right] d \theta
$$

H-ARQ 시스템에서 서브프레임의 전송 순서를 조 정하는 재전송 패턴에 따른 채널 용량을 수식 (3)과 (6)을 사용하여 계산할 수 있다.

그림 1 과 2 는 각각 $\mathrm{H}-\mathrm{ARQ}$ 시스템에서 다양한 서 브프레임 재전송 패턴에 대한 채널 용량과 BER 성능 을 보여준다. 그림에서 $\mathrm{ECPA}$ 와 $\mathrm{CCC}$ 는 각각 균등 결 합 전력 할당 패턴과 기존의 (conventional) 체이스 결 합을 의미한다. 이러한 분석을 위하여 수식 (1)에서 $d$ 가 1 인 단일 딥 페이딩 채널을 고려한다. 또한 오류 정정을 위하여 부호 길이 $N_{s}=2304$ 이고, 가장 짧은 사이클의 길이를 의미하는 거스 $(\mathrm{girth})$ 가 6 인 $(3,6)$ 규칙 (regular) block-type LDPC (B-LDPC) 부호를 랜덤하게 생성한다. 하나의 패킷에 서브프레임의 개수 를 $M=24$ 로 설정하고, 패킷은 BPSK 변조를 사용하 여 전송된다고 가정한다. 첫 번째 전송에서는 서브프 레임의 순서를 별도로 조정하지 않고 순차적으로 전 송이 수행 $(1,2,3,4,5,6,7,8,9,10,11,12,13$, $14,15,16,17,18,19,20,21,22,23,24)$ 된다. 그 러면, 그림 1 에서 $[-1.75 \mathrm{~dB},-0.5 \mathrm{~dB}]$ 사이의 $E_{b} / N_{0}$ 구간에서 채널 용량은 균등 결합 전력 할당을 위한 서브프레임 재전송 패턴 $(13,14,15,16,17,18$, $19,20,21,22,23,24,1,2,3,4,5,6,7,8,9,10$, $11,12)$, 재전송 패턴 I $(10,8,15,19,17,18,3,13$, $2,22,20,6,23,12,9,21,1,5,7,24,16,14,11$, 4), 재전송 패턴 II $(13,14,2,9,5,19,18,1,3,21$, $8,17,15,7,16,24,10,4,11,12,6,20,23,22)$, 재전송 패턴 III $(21,8,7,22,1,20,4,2,3,11,17$, $12,19,23,10,24,13,18,6,16,9,15,14,5)$, 재전 송 패턴 IV $(16,5,24,18,21,7,6,4,12,8,13,15$, $9,10,1,17,2,3,23,19,22,11,20,14)$, 그리고 기존의 체이스 결합을 위한 재전송 패턴 $(1,2,3,4$, $5,6,7,8,9,10,11,12,13,14,15,16,17,18,19$, $20,21,22,23,24)$ 순으로 크기가 크다는 사실을 확 인할 수 있다. 여기서 네 가지 재전송 패턴은 채널 용 량과 BER 성능 사이의 관계를 극명하게 보여주기 위 하여 임의로 선택되었다. 예측한 바와 같이, 그림 2 로 부터 BER 성능이 채널 용량의 크기 순서대로 우수함 을 확인할 수 있다. 다시 말해서, 어떤 서브프레임 재 전송 패턴의 채널 용량이 클수록 BER 성능도 더 우 수하다는 경향성을 확인할 수 있다. 그러므로 H-ARQ 시스템에서 패킷의 재전송시에 서브프레임 재전송 패 턴에 따른 BER 성능을 채널 용량을 계산하여 간단하 게 예측할 수 있다. 또한 채널 용량을 사용한 분석을 통하여 각 서브프레임에 대하여 균등 결합 전력 할당 


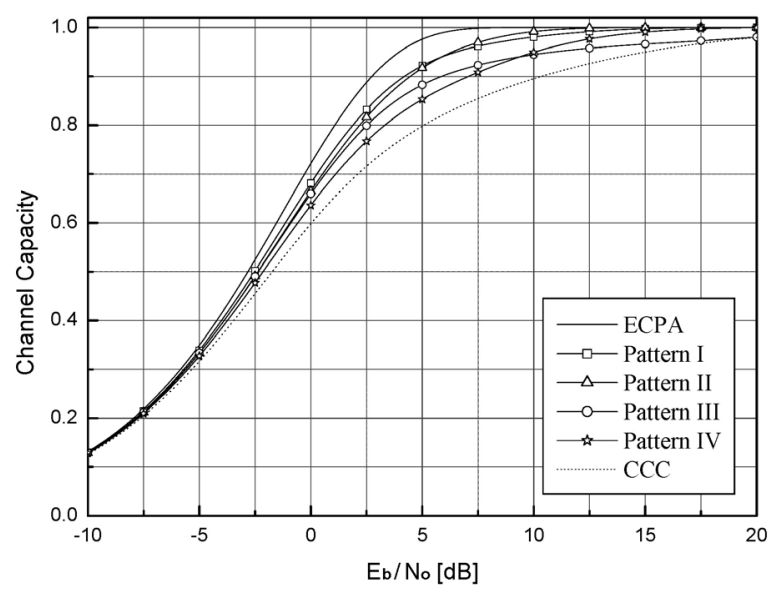

그림 1. 다양한 서브프레임 재전송 패턴에 대한 채널 용량 Fig. 1. Channel capacity according to various subframe reordering patterns

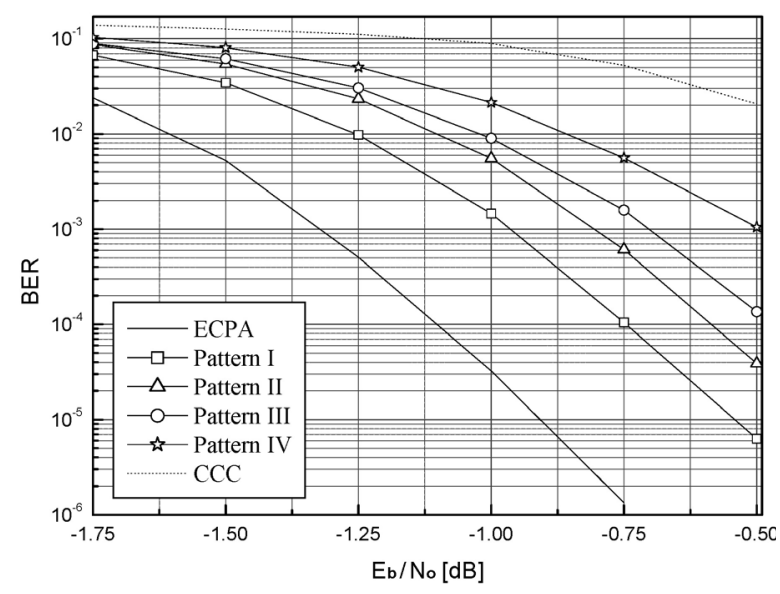

그림 2. 다양한 서브프레임 재전송 패턴에 대한 BER 성능 Fig. 2. BER performance according to various subframe reordering patterns

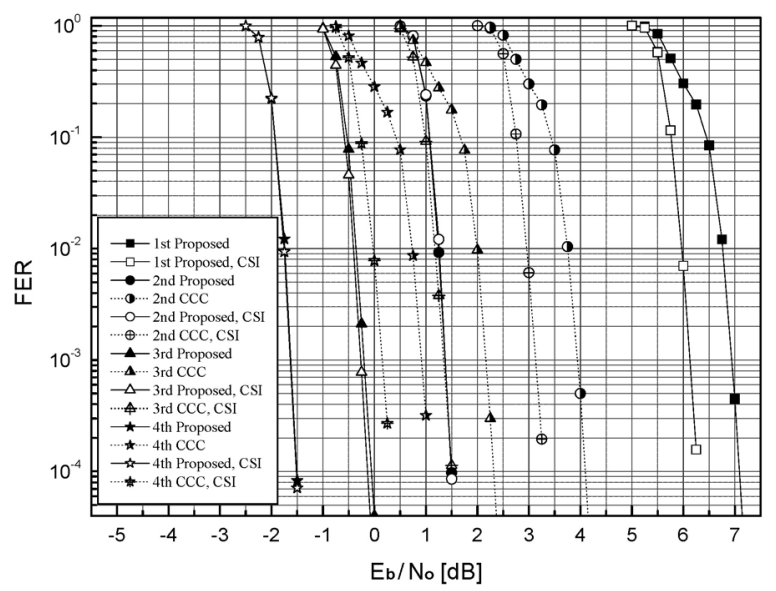

그림 3. 서브프레임 전송 순서를 조정하는 재전송 기법들의 FER 성능 비교

Fig. 3. FER performance comparison of subframe reordering schemes
을 달성하도록 서브프레임의 순서를 조정하는 재전송 패턴의 채널 용량이 가장 큰 값을 갖게 되어 그에 대 응하는 BER 성능이 가장 우수하다는 사실을 규명할 수 있다. 유사하게, 두 번의 딥 페이딩 (double deep fading) 채널과 세 번의 딥 페이딩 (triple deep fading) 채널에 대해서도 채널 용량과 BER 성능 사이의 상관 관계를 확인할 수 있다.

\section{V. 모의실험 결과}

그림 3은 IEEE $802.16 \mathrm{e}$ 표준 ${ }^{[10]}$ 에 제시된 부호 길 이가 2304이고 부호율이 1/2인 LDPC 부호에 대하여 최대 전송 횟수가 4회로 제한된 $\mathrm{H}-\mathrm{ARQ}$ 를 지원하는 시스템을 고려하였을 때, 서브프레임 순서를 조정하는 재전송 방법과 기존 체이스 결합 기법의 프레임 오류 율 (frame error rate: FER) 성능을 비교한다. 여기서 하나의 패킷 내의 서브프레임의 개수 $M=8$ 이다. 또 한 패킷은 16-QAM 변조 방식을 사용하여 전송되며, 채널 모델은 수식 (1)에 주어진 $d=1$ 인 two-ray 전파 모델을 고려한다. 아울러 LDPC 부호의 복호는 BP 반 복 복호 알고리즘을 사용하여 수행되었고, 특별한 언 급이 없는 한 최대 반복 횟수는 50 회이다. 또한 그림 3 의 범례에서 $\mathrm{CCC}$ 는 기존의 체이스 결합 방법에 따 른 재전송을 나타내며, CSI는 채널 상태 정보를 이용 할 수 있는 환경을 의미한다.

그림 3으로부터, H-ARQ 시스템에서 채널 용량을 기반으로 균등 결합 전력 할당을 위하여 제안된 서브 프레임의 전송 순서를 조정하는 재전송 방법이 CSI를 이용할 수 있는 시스템과 그렇지 못한 시스템에서 모 두 기존의 체이스 결합 방법보다 성능이 우수하다는 사실을 확인할 수 있다. 또한, 첫 번째 전송에서 CSI 를 이용하여 서브프레임의 전송 순서를 조정하는 전 송 방법이 원래 서브프레임 순서대로 전송 $\left(\left\{M_{1}, M_{2}, M_{3}, M_{4}, P_{1}, P_{2}, P_{3}, P_{4}\right\}\right)$ 하는 경우보다 성능 이 우수함을 확인할 수 있다. 여기서 $M$ 과 $P$ 는 각각 한 패킷 내의 메시지와 패리티 부분을 나타내며, 부호 율이 $1 / 2$ 인 LDPC 부호에 대하여 패킷 내의 8 개의 서 브프레임은 각각 4 개의 서브프레임으로 구성된 메시 지와 패리티 부분으로 나눌 수 있다. 하지만 두 번째 전송에서는 제안된 $\mathrm{H}-\mathrm{ARQ}$ 기법을 사용한 OFDM 시 스템의 FER 성능은 CSI 이용 유무에 의존하지 않는 다. 즉, $\mathrm{CSI}$ 를 이용할 수 없는 환경에서 각 서브프레 임의 결합 전력이 균등하도록 서브프레임의 전송 순 서를 조정하는 재전송 방법은 CSI를 완전히 이용하는 
시스템에서 제안된 방법과 성능이 일치함을 확인할 수 있다.

CSI를 이용할 수 없는 시스템에서 서브프레임 재전 송 패턴을 결정하기 위하여 각 서브프레임의 평균 전 력을 계산할 수 있다. CSI를 이용할 수 없는 조건에서 는 $\theta$ 값을 알 수 없으므로 전력을 평균 관점에서 계산 한다. 단일 딥 페이딩 채널에 대하여 $|h(s)|^{2}$ 는 다음 과 같이 표현할 수 있다.

$$
|h(s)|^{2}=2+2 \cos \left(\theta+\frac{2 \pi s}{N_{s}}\right)
$$

그러므로 각 서브프레임의 평균 전력을 다음과 같 이 유도할 수 있다.

$$
p_{i}=\frac{1}{72} \int_{\frac{\pi}{4} i}^{\frac{\pi}{4}(i+1)} \sum_{s=0}^{71}|h(s)|^{2} d \theta
$$

수식 (7)과 (8)로부터, 각 서브프레임의 평균 전력 을 다음과 같이 나타낼 수 있다.

$$
p_{i}=\frac{1}{72} \int_{\frac{\pi}{4} i}^{\frac{\pi}{4}(i+1)} \sum_{s=0}^{71}\left[2+2 \cos \left(\theta+\frac{2 \pi s}{N_{s}}\right)\right] d \theta
$$

여기서 $p_{i}, 0 \leqq i \leqq 7$,는 $i$-번째 서브프레임의 평균 전력을 나타내며, 각 서브프레임은 $72(=576 / 8)$ 개의 16-QAM 심볼을 포함한다. 앞서 제시한 전력 계산을 기반으로 두 번째 전송에서 결합 전력을 균등하게 하 는 서브프레임 재전송 패턴을 $\left\{P_{1}, P_{2}, P_{3}, P_{4}\right.$, $\left.M_{1}, M_{2}, M_{3}, M_{4}\right\}$ 로 결정할 수 있다.

세 번째 전송에서는 첫 번째 전송에서와 유사한 서 브프레임 전송 패턴을 선택할 수 있으며, 그림 3은 그 에 따른 FER 성능을 보여준다. 주어진 채널에 대한 평균화 효과가 두 번째 전송까지 완료되어 세 번째 전 송 과정에서 각 서브프레임의 전력을 균등하게 하는 것이 불가능하기 때문에, $\mathrm{CSI}$ 를 이용하지 못하는 환 경에서 서브프레임 순서를 조정하는 재전송 방법은 $\mathrm{CSI}$ 를 이용하는 경우에 서브프레임 순서를 조정하는 재전송 방법보다 성능의 열화를 보인다. 그러나 균등 결합 전력 할당에 의한 채널 평균화 효과의 이득은 두 번째 전송 과정에서의 서브프레임 재전송 패턴의 사 용으로 거의 포화 (saturation)되어, 세 번째 전송시 CSI 이용 유무에 따른 두 가지 재전송 방법 사이의 성 능 차이는 미미하다. 마지막 전송시 두 가지 재전송 방법의 FER 성능은 H-ARQ 시스템의 네 번째 전송 에서 균등 결합 전력 할당이 이루어지기 때문에 동일
하다.

그러므로 균등 결합 전력 할당을 보장하도록 제안 된 서브프레임 순서를 조정하는 재전송 방법은 CSI 이용 유무에 관계없이 기존 체이스 결합 방법보다 복 호 복잡도를 증가시키지 않으면서도 주목할 만한 성 능 개선을 보여준다. 또한 CSI가 제공되지 않는 $\mathrm{H}-\mathrm{ARQ}$ 시스템에서도 서브프레임 순서를 조정하는 재전송 방법은 복잡도의 증가 없이 CSI를 이용한 경 우와 거의 동일한 신뢰도로 오류를 복원할 수 있다.

$\mathrm{H}-\mathrm{ARQ}$ 전송 과정에서 재전송 횟수를 줄일 수 있는 서브프레임 재전송 기법과 계층 복호 방법을 적용하 여 $\mathrm{LDPC}$ 로 부호화된 $\mathrm{OFDM}$ 시스템의 성능 및 복잡 도를 개선할 수 있다. 이제 LDPC로 부호화된 OFDM 시스템에서 계층 복호 방법을 적용하여 성능의 수렴 속도 개선에 대하여 살펴보자. 그림 4와 5는 계층 복 호 방법을 적용하여 H-ARQ 시스템의 최대 전송 횟수 가 2회일 경우에 다양한 반복 횟수에 따른 FER 성능 을 보여준다. 여기서 $p$ 는 체크 노드 subset의 개수를 나타내며 계층 복호가 가능하도록 하기 위하여 $p=6 L$ 로 설정한다. 아울러 $p=1$ 인 경우는 기존의 $\mathrm{BP}$ 반복복호 알고리즘을 사용한 경우를 의미한다. 또 한 $I$ 는 반복 복호 과정에서 최대 반복 (iteration) 횟수 를 나타낸다. 그림 3에서 사용한 동일한 $\mathrm{LDPC}$ 부호 와 시스템 설정을 적용하여 모의실험을 진행한다. 그 림 4는 CSI를 이용할 수 없는 H-ARQ 시스템에서 서 브프레임 순서를 조정하는 재전송 방법과 기존 체이 스 결합 기법에 대하여, 기존의 $\mathrm{BP}$ 반복 복호 방법과 계층 복호 방법의 수렴 속도를 보여준다. 그림 5는 $\mathrm{CSI}$ 를 이용할 수 있는 $\mathrm{H}-\mathrm{ARQ}$ 시스템에서 기존의 BP 반복 복호 방법과 계층 복호 방법의 수렴 속도를 보여 준다. 기존 $\mathrm{BP}$ 반복 복호 방법과 계층 복호 방법을 비 교하면 동일한 반복 횟수에 대하여 계층 복호 방법에 대한 FER 성능이 더 우수함을 확인할 수 있다. 특히 반복 횟수가 작을수록 그 성능의 차이를 두드러지게 확인할 수 있다.

그림 4와 5로부터, 계층 복호 방법의 25회 반복의 성능이 기존 $\mathrm{BP}$ 복호 방법의 50회 반복의 성능과 일 치함을 확인할 수 있다. 그러므로 두 방법 모두 한 번 의 반복에 이용되는 복호 과정에서의 연산량이 동일 하기 때문에, 동일한 복호 성능을 보장하면서도 연산 의 복잡도는 절반으로 감소한다는 사실을 알 수 있다. 이는 H-ARQ 시스템을 지원하는 실제 무선 통신 시스 템 환경의 복호기 구현시 복잡도를 줄일 수 있다는 의 미에서 장점을 갖는다. H-ARQ 시스템의 최대 전송 횟수를 3 회 혹은 4회로 설정할 경우에도 2회로 설정 


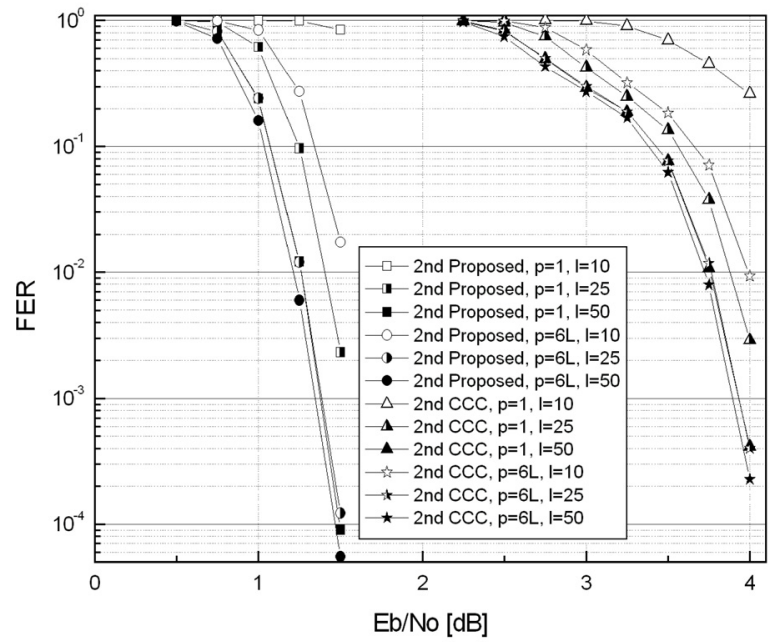

그림 4. CSI를 이용하지 못하는 경우에 다양한 복호 방법과 반복 횟수 사용에 따른 FER 성능

Fig. 4. FER performance using various decoding schemes and iterations for cases of no CSI

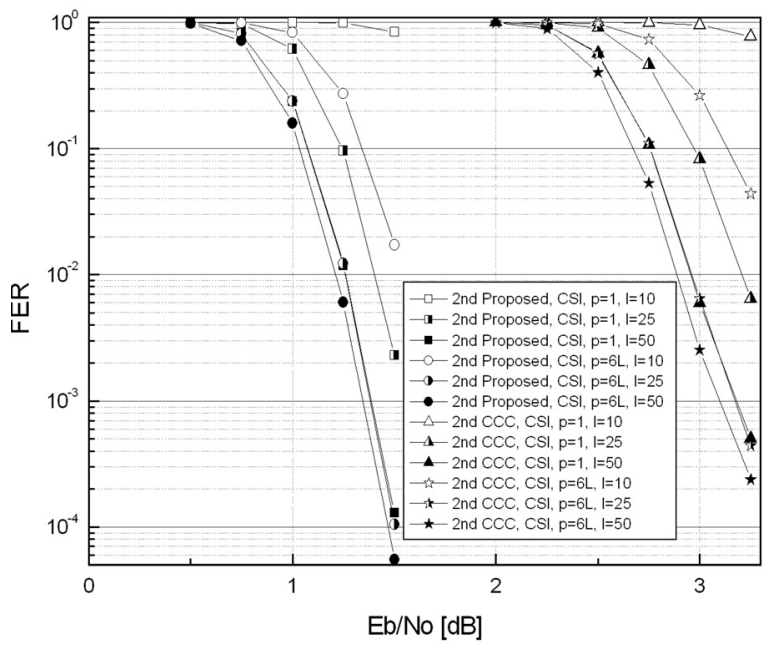

그림 5. CSI를 이용할 수 있는 경우에 다양한 복호 방법과 반복 횟수 사용에 따른 FER 성능

Fig. 5. FER performance using various decoding schemes and iterations for cases of CSI

한 결과와 유사하게 계층 복호 방법의 수렴 속도 개선 을 확인할 수 있다.

\section{VI. 결 론}

본 논문은 type I H-ARQ 시스템에서 LDPC로 부호화된 $\mathrm{OFDM}$ 서브프레임의 전송 순서를 균등 결합 전력이 할당되도록 조정한 재전송 방법을 소 개하고, 수렴 속도를 개선할 수 있는 계층 복호 방 법을 적용하여 $\mathrm{H}-\mathrm{ARQ}$ 시스템의 성능 개선을 확인 한다. 균등 결합 전력 할당에 의한 재전송 패턴의
성능 개선 여부는 채널 용량을 이용하여 분석할 수 있다. 구체적으로 채널 용량이 더 큰 서브프레임 재 전송 패턴에 대한 $\mathrm{BER}$ 성능이 더 좋다는 사실이 모의실험을 통하여 규명되었기 때문에, H-ARQ 시 스템에서 패킷의 재전송시에 서브프레임의 재전송 패턴에 따른 BER 성능은 채널 용량을 계산하여 간 단하게 예측할 수 있다. OFDM 시스템에서 매우 느리게 변하는 페이딩 채널을 가정할 경우에 기존 체이스 결합 방식은 채널 용량을 사용하여 서브프 레임 전송 순서를 조정하는 재전송 방법으로 변경 이 가능하다. 그 결과로 각 서브프레임에 대하여 균 등 결합 전력 할당을 보장하는 서브프레임 재전송 패턴은 채널 용량을 최대로 하며, 임의의 다른 서브 프레임 전송 순서 조정을 통한 재전송 패턴보다 성 능이 우수하다는 사실을 알 수 있다. 또한 모의실험 결과를 통하여 균등 결합 전력 할당을 만족하도록 서브프레임 순서를 조정하는 재전송 방법은 기존 체이스 결합 방법보다 복호 복잡도를 증가시키지 않으면서도 주목할 만한 성능 개선을 보임을 확인 할 수 있다. 아울러 제안된 재전송 방법은 overhead 를 증가시킬 수 있는 $\mathrm{CSI}$ 를 전송할 필요가 없는 장 점을 갖는다. 그러므로 $\mathrm{CSI}$ 가 제공되지 않는 H-ARQ 시스템에서도 OFDM 서브프레임 순서를 조정하는 재전송 방법은 복잡도의 증가 없이 $\mathrm{CSI}$ 를 이용한 경우와 비교하여 거의 동일한 신뢰도로 오 류를 복원할 수 있다. 마지막으로 페이딩 환경의 type I H-ARQ 시스템에서 서브프레임 재전송 방법 을 사용할 때, 복호 과정에서 계층 복호 방법이 기 존 $\mathrm{BP}$ 반복 복호 방법보다 성능의 수렴 속도가 우 수하다는 사실을 확인할 수 있다. 두 방법 모두 한 번의 반복에 사용되는 계산량이 동일하기 때문에, 계층 복호 방법은 동일한 복호 성능을 보장하면서 도 복호 복잡도를 줄일 수 있기 때문에, H-ARQ 시 스템을 지원하는 실제 무선 통신 시스템 환경의 복 호기 구현시 계산 복잡도를 줄일 수 있는 장점을 갖는다.

\section{References}

[1] R. V. Nee and R. Prasad, OFDM for Wireless Multimedia Communications, Artech House, 2000.

[2] R. G. Gallager, Low-Density Parity-Check Codes, MIT Press, 1963.

[3] T. J. Richardson and R. L. Urbanke, "The 
capacity of low-density parity- check codes under message-passing decoding," IEEE Trans. Inf. Theory, vol. 47, no. 2, pp. 599-618, Feb. 2001.

[4] M.-H. Jang, B. Shin, W.-M. Park, J.-S. No, and D.-J. Shin, "Convergence speed analysis and layered decoding of block-type LDPC codes," IEICE Trans. Commun., vol. E92-B, no. 7, pp. 2484-2487, July 2009.

[5] M.-H. Jang, B.-K. Shin, W.-M. Park, J.-S. No, and I.-S. Jeon, "Decoding method of LDPC codes in IEEE 802.16e standards for improving the convergence speed," J. KICS, vol. 31, no. 12C, pp. 1143-1149, Dec. 2006.

[6] D. Chase, "Code combining: a maximum-likelihood decoding approach for combining an arbitrary number of noisy packets," IEEE Trans. Commun., vol. 33, no. 5, pp. 385-393, May 1985.

[7] M.-H. Jang, B. Shin, J.-S. No, S.-H. Kim, and D.-J. Shin, "A new criterion for retransmission in type I H-ARQ schemes of LDPC coded OFDM systems," in Proc. IEEE Veh. Technol. Conf. (VTC 2009-Fall), pp. 1-4, Anchorage, U.S.A, Sep. 2009.

[8] P. Balaban and V. P. Dewal, "Statistical distribution of parameters in a variable delay two-ray propagation model," in Proc. IEEE Global Telecommun. Conf. (GLOBECOM), pp. 59-64, Dallas, U.S.A., Nov. 1989.

[9] T. M. Cover and J. A. Thomas, Elements of Information Theory, 2nd Ed., John Wiley \& Sons, Inc., 2006.

[10] IEEE 802.16 Working Group, IEEE Standard for Local and Metropolitan Area Networks, Part 16: Air Interface for Fixed and Mobile Broadband Wireless Access Systems, IEEE Standard 802.16e-2005, Feb. 2006.
장 민 호 (Min-Ho Jang)

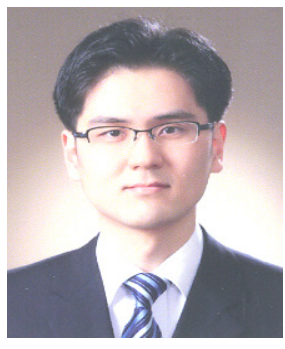

2002년 8월 연세대학교 전기 전자공학부 공학사

2004년 8월 서울대학교 전기 컴퓨터공학부 공학석사 2009년 2월 서울대학교 전기

컴퓨터공학부 공학박사 2009년 3월 2011년 8월 삼성

전자 $\mathrm{DMC}$ 연구소 책임연구원

2011년 9월 현재 울산과학대학교 전기전자공학부 조교수

<관심분야> 디지털통신, 이동통신시스템, 오류정정 부호, $\mathrm{LDPC}$ 부호, OFDM 